\title{
AN OUTPATIENT SURVEY OF WHEEZING PAEDIATRIC PATIENTS IN A TERTIARY CARE HOSPITAL
}

\author{
Gunjan Kela Mehrotra1, Parul Jain², Aayush Gupta ${ }^{3}$, Swati Mulye ${ }^{4}$
}

1Associate Professor, Department of Paediatrics, SAMC and PGI, Indore, Madhya Pradesh.

2Junior Resident, Department of Paediatrics, SAMC and PGI, Indore, Madhya Pradesh.

3Junior Resident, Department of Paediatrics, SAMC and PGI, Indore, Madhya Pradesh.

${ }^{4}$ Professor, Department of Paediatrics, SAMC and PGI, Indore, Madhya Pradesh.

\begin{abstract}
BACKGROUND

Wheezing is a common condition in paediatric practice. It can be defined as a musical sound, high-pitched and continuous, emitting from the chest during breath exhalation. Although, almost $50 \%$ of children experiences wheeze in the first 6 years of life, only $40 \%$ of them will report continued wheezing symptoms after childhood. During the act of inspiration air enters the alveoli through larynx, trachea and bronchi and during expiration in the opposite direction. Vibrations caused by the passage or movement of air through these structures results in the production of respiratory sound. Expiratory thoracic muscles compress the lower chest, abdominal muscles contract pushing diaphragm up in an attempt to squeeze the air out of the lung resulting in raised intrapulmonary pressure. The air now escapes under high pressure through the narrowed bronchial lumen producing cooy sound, so an outpatient survey was done to evaluate the common causes of wheezing in paediatric patients.
\end{abstract}

\section{MATERIALS AND METHODS}

An outpatient survey of wheezing was conducted from $1^{\text {st }}$ October 2017 to $31^{\text {st }}$ December 2017. During this period study comprised of 150 patients of age group of 2 months to 14 years, randomly selected by simple random sampling method [Lottery method] who reported with conditions giving rise to wheezing. Informed consent was obtained from the parents or guardians of the paediatric patients. These children were investigated after taking family, dietetic, allergic and helminthic history. Most of the mothers brought their infants with the complaint of noisy breathing, but when examined many of them had either transmitted throat sounds or there was nasal block without any lung signs. On an average, about 15 - 20 cases per week were coming to an outpatient department with this complaint. These cases were investigated relevantly and followed upto 3 months. Obtained data were arranged according to characteristics and were expressed as a number and percentage of respondents and were analysed using the SPSS Version 17 software.

\section{RESULTS}

Most common aetiology is of bronchial asthma in 85 patients. Maximum patients of bronchial asthma (65\%), worm infestation $(68 \%)$ and tropical eosinophilia (50\%) were in 5 - 9 years' age group. Maximum patients in case of bronchiolitis were in 7 - 12 months' age group. Among 85 cases of bronchial asthma 55 were male patients and 30 were female and among 15 cases of bronchiolitis 7 cases were male and 8 cases were female. Among 22 cases of worm infestation 14 were male and 8 were female and among 10 cases of tropical eosinophilia 6 were male and 4 were female.

\section{CONCLUSION}

This outpatient survey revealed wheezing or noisy breath as one of the common symptoms with which children are coming to outpatient. The present study found apart from bronchial asthma, acute respiratory infections, worm infestations and tropical eosinophilia constituted large percentage of cases. Wheezing is a symptom of many diseases, the cause of which must be thoroughly investigated for proper management of the case. Because of the small size of bronchi and abundancy of lymphoid tis sue and relatively frequent infections, allergic disorders during childhood, the airway is more prone to obstruction resulting in difficulty not only during inspiration, but much more so in expiration.

\section{KEYWORDS}

Wheezing, Asthma, Bronchiolitis.

HOW TO CITE THIS ARTICLE: Mehrotra GK, Jain P, Gupta A, et al. An outpatient survey of wheezing paediatric patients in a tertiary care hospital. J. Evolution Med. Dent. Sci. 2018;7(14):1695-1698, DOI: 10.14260/jemds/2018/383

\section{BACKGROUND}

Wheezing is a common condition in paediatric practice. It can be defined as a musical sound, high-pitched and continuous, emitting from the chest during breath exhalation.

'Financial or Other Competing Interest': None.

Submission 22-02-2018, Peer Review 17-03-2018,

Acceptance 25-03-2018, Published 02-04-2018.

Corresponding Author:

Dr. Gunjan Kela Mehrotra,

\#201 A, Block OM, Gurudev Complex,

SCH 54, Vijay Nagar, Indore-452010, Madhya Pradesh.

E-mail:drgunjankela@yahoo.com

DOI: $10.14260 /$ jemds $/ 2018 / 383$
Although, almost $50 \%$ of children experiences wheeze in the first 6 years of life, only $40 \%$ of them will report continued wheezing symptoms after childhood.[1]

During the act of inspiration air enters the alveoli through larynx, trachea and bronchi and during expiration in the opposite direction. Vibrations caused by the passage or movement of air through these structures results in the production of respiratory sound. Normally inspiration is an active effort, while expiration is passive, short, about onethird of inspiration, and is assisted by elastic recoil of lung. Any factor that causes obstruction of airway by obstructing the lumen or causing extrinsic pressure, the difficulty in respiration is experienced during inspiration and well as in 
expiration.[2] The upper the site of obstruction like larynx, trachea, more is the inspiratory dyspnoea, thus producing harsh vibratory high pitched shrill, crowing noise which is known as stridor. Inspiratory dyspnoea is associated with expiratory distress, because during expiration due to increased intrathoracic pressure the bronchiolar lumen further narrows. The more peripheral the obstruction to the airway, the more is the difficulty expressed during expiration resulting in hissing sound which is known as wheezing.[3] Thus, obstruction to the airway whether upper or lower, the difficulty in breathing is experienced both during inspiration and expiration. However, because of the natural recoiling during expiration greater effort is needed during the act. Expiratory thoracic muscles compress the lower chest, abdominal muscles contract pushing diaphragm up in an attempt to squeeze the air out of the lung resulting in raised intrapulmonary pressure, the air now escapes under high pressure through the narrowed bronchial lumen producing cooy sound, ${ }^{[4]}$ so an outpatient survey was done to evaluate the common causes of wheezing in paediatric patients.

\section{MATERIALS AND METHODS}

An outpatient survey of wheezing was conducted from $1^{\text {st }}$ October 2017 to 31st December 2017. During this period study comprised of 150 patients of age group of 2 months to 14 years, randomly selected by simple random sampling method [Lottery method] who reported with conditions giving rise to wheezing. Informed consent was obtained from the parents or guardians of the paediatric patients. These children were investigated after taking family, dietetic, allergic and helminthic history. Most of the mothers brought their infants with the complaint of noisy breathing, but when examined many of them were either transmitted throat sounds or there was nasal block without any lung signs. On an average, about 15 - 20 cases per week were coming to an outpatient department with this complaint. These cases were investigated relevantly and followed upto 3 months. Obtained data was arranged according to characteristics and was expressed as a number and percentage of respondents and were analysed using the SPSS Version 17 software.

Since the study duration was short, we had to limit the sample size for convenience.

\section{RESULTS}

\begin{tabular}{|c|c|}
\hline Bronchial asthma & 85 \\
\hline Worm infestation & 22 \\
\hline Acute bronchiolitis & 15 \\
\hline Tropical eosinophilia & 10 \\
\hline Post measles bronchopneumonia & 8 \\
\hline Acute bronchitis & 7 \\
\hline Primary complex & 3 \\
\hline $\begin{array}{c}\text { Table 1. Shows Distribution of Outpatient } \\
\text { Cases according to Aetiology }\end{array}$ \\
\hline
\end{tabular}

Most common aetiology is of bronchial asthma in 85 patients.

\begin{tabular}{|c|c|c|}
\hline Age & Patients & Percentage [\%] \\
\hline Bronchial Asthma & & \\
\hline $1-4$ yrs. & 16 & $19 \%$ \\
\hline $5-9$ yrs. & 55 & $65 \%$ \\
\hline $10-12$ yrs. & 14 & $16 \%$ \\
\hline Bronchiolitis & & \\
\hline $2-3$ months & 2 & $13 \%$ \\
\hline $4-6$ months & 3 & $20 \%$ \\
\hline $7-12$ months & 7 & $47 \%$ \\
\hline $1-2$ yrs. & 3 & $20 \%$ \\
\hline Worm Infestation & & $18 \%$ \\
\hline $1-4$ yrs. & 4 & $68 \%$ \\
\hline $5-9$ yrs. & 15 & $14 \%$ \\
\hline $10-12$ yrs. & 3 & \\
\hline Tropical & & $30 \%$ \\
Eosinophilia & & $50 \%$ \\
\hline 1-4 yrs. & 3 & $20 \%$ \\
\hline 5-9 yrs. & 5 & \\
\hline $10-12$ yrs. & 2 & to Age \\
\hline Table 2. Showing Distribution of Patients according & \\
\hline
\end{tabular}

Table 1 describes the distribution of patients according to age. Maximum patients of bronchial asthma (65\%), worm infestation (68\%) and tropical eosinophilia (50\%) were in 59 years' age group. Maximum patients in case of bronchiolitis were in 7-12 months' age group. Among 85 cases of bronchial asthma, 55 were male patients and 30 were female (Figure 1).

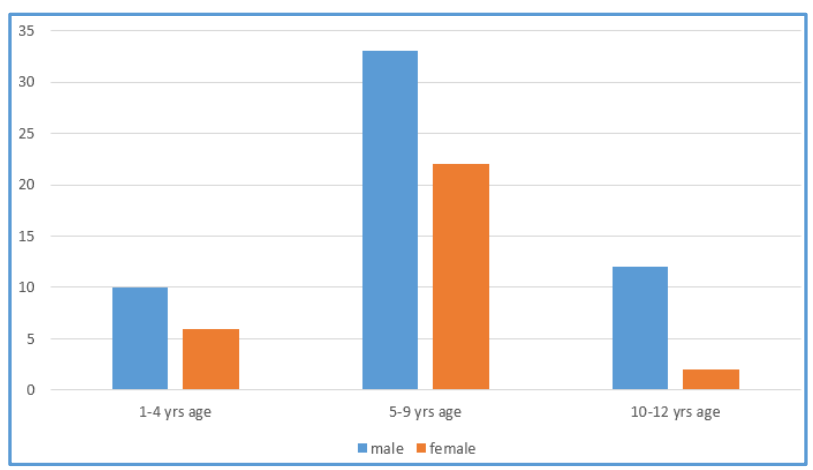

Figure 1. Age and Sex Wise Distribution of Bronchial Asthma

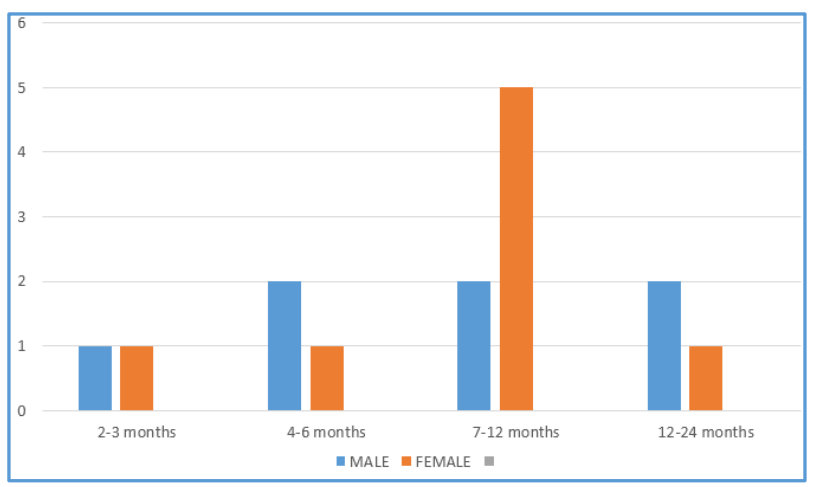

Figure 2. Age and Sex Wise Distribution in Bronchiolitis 
Among 15 cases of bronchiolitis, 7 cases were male and 8 cases were female (Figure 2).

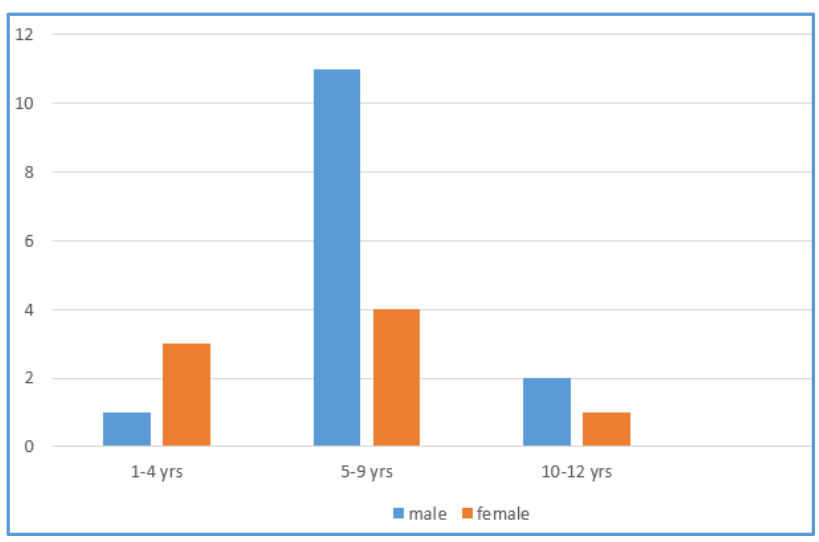

Figure 3. Age and Sex Wise Distribution in Worm Infestation

Among 22 cases of worm infestation, 14 were male and 8 were female (Figure 3). Among 10 cases of tropical eosinophilia, 6 were male and 4 were female.

\section{DISCUSSION}

Wheeze is defined as a continuous high-pitched sound with musical quality emitting from the chest during expiration. It is one of a number of forms of noisy breathing in preschool children.[5] Parents differ widely in their understanding and definition of wheeze. Some think it is a sound such as whistling, squeaking or gasping, whereas others define it as a different rate or style of breathing, or think it is the same as cough. ${ }^{[5-9]}$ If based on parental report alone, children may be labelled as having wheeze when they do not. If possible, therefore, wheeze should be confirmed by a health professional bearing in mind that not all healthcare workers are equally accurate in estimating the severity of wheeze.[10]

In the present study, bronchial asthma was diagnosed in maximum number of wheezing patients. The aetiology, pathophysiology, natural history and presentation of childhood asthma are so variable and complex that a universally acceptable definition cannot be reached at. According to WHO, asthmatic bronchitis, allergic bronchitis, bronchial asthma, all these three entities are to be included under the terminology of bronchial asthma.[11]

It has been time and again stated that asthma in childhood continues to be underdiagnosed and untreated, while labels such as "wheezy bronchitis," "asthmatic bronchitis" and "allergic bronchitis," "wheeze associated respiratory illness" are frequently used to spare the parental anxiety. Asthma is often known as reactive airway disease with the asthma complex including wheezy bronchitis, asthmatic bronchitis, viral associated wheezing and atopy related asthma. ${ }^{[12]}$

The American Thoracic Society defines asthma as a disease characterised by increased responsiveness of the trachea and bronchi to various stimuli and is manifested by a widespread narrowing of the airways that change in severity spontaneously or as a result of therapy.[13]

Tabachnik E et al stated that any baby with recurrent episodes of wheezing ( 3 or more) be considered as having asthma, regardless of age of onset, evidence of atopy, apparent precipitating cause of wheeze or frequency of wheeze.[4] This definition excludes specific causes of wheeze other than asthma.

Skoner et al for practical purposes defined asthma as three or more episodes of reversible bronchospasm (i.e. acute onset of wheezing and airway obstruction that lessens after therapy).[14] Children in population that migrate to urban area from rural areas begin to experience a much higher prevalence of asthma when followed over a period than similar children who remain in the rural areas. The urbanised environment increases exposure to new allergens and irritants.[15]

Thus present study found that apart from bronchial asthma, acute respiratory infections, worm infestations and tropical eosinophilia constituted large percentage of cases.

Other causes of wheezing in children are infections, postviral wheezing, tuberculosis (e.g. glandular compression of airways), HIV disease (e.g. lymphocytic interstitial pneumonia), congenital/perinatal problems, tracheomalacia, cystic fibrosis, chronic lung disease of the newborn, congenital malformation causing narrowing of the intrathoracic, airways, primary ciliary dyskinesia syndrome, immune deficiency, congenital heart disease, mechanical problems, foreign body aspiration and gastro-oesophageal reflux disease (GERD).[16]

\section{Limitations}

Since the study duration was short, we had to limit the sample size for convenience.

\section{CONCLUSION}

This outpatient survey revealed wheezing or noisy breath as one of the common symptoms with which children are coming to outpatient. The present study found apart from bronchial asthma, acute respiratory infections, worm infestations and tropical eosinophilia constituted large percentage of cases. Wheezing is a symptom of many diseases, the cause of which must be thoroughly investigated for proper management of the case. Because of the small size of bronchi and abundancy of lymphoid tissue and relatively frequent infections allergic disorders during childhood, the airway is more prone to obstruction resulting in difficulty not only during inspiration but much more so on expiration.

\section{REFERENCES}

[1] Tenero L, Tezza G, Cattazzo E, et al. Wheezing in preschool children. Early Hum Dev 2013;89(Suppl 3):S13-S7.

[2] Kasliwal BM, Sethis JP, Sogani IC. The clinical study of bronchial asthma. Ind J Chest Dis 1959;1:95.

[3] Viswanathanm R. A study of clinical profile of bronchial asthma. Ind Chest Dis 1964;6:109.

[4] Tabachnik E, Levison H. Postgraduate course presentation. Infantile bronchial asthma. J Aller Clin Imm 1981;67(5):339-47.

[5] Elphick HE, Sherlock P, Foxall G, et al. Survey of respiratory sounds in infants. Arch Dis Child 2001;84(1):35-9.

[6] Michel G, Silverman M, Strippoli MP, et al. Parental understanding of wheeze and its impact on asthma prevalence estimates. Eur Respir J 2006;28(6):112430 . 


\section{Jemds.com}

[7] Elphick HE, Ritson S, Rodgers H, et al. When a "wheeze" is not a wheeze: acoustic analysis of breath sounds in infants. Eur Respir J 2000;16(4):593-7.

[8] Cane RS, Ranganathan SC, McKenzie SA. What do parents of wheezy children understand by "wheeze"? Arch Dis Child 2000;82(4):327-32.

[9] Cane RS, McKenzie SA. Parents' interpretations of children's respiratory symptoms on video. Arch Dis Child 2001;84(1):31-4.

[10] Levy ML, Godfrey S, Irving CS, et al. Wheeze detection: recordings vs. assessment of physician and parent. J Asthma 2004;41(8):845-53.

[11] Sly RM. Allergic disorders. In: Behrman RE, Kleigman RM, Arvin AM, eds. Nelson text book of paediatrics book I. 15th edn. Bangalore: Prism Books Pvt Ltd., 1996: p. 628-41.

[12] Speight ANP, Lee DA, Hey EN. Under diagnosis and under treatment of asthma in childhood. Br Med J 1983;286(6373):1253-6.

\section{Original Research Article}

[13] American Thoracic Society: chronic bronchitis, asthma and pulmonary emphysema. A statement by committee on diagnostic standards for nontuberculosis respiratory disease. Am Rev Respi Dis 1962;85:762-9.

[14] Skoner D, Caliguire S. The wheezing infant PCNA. 1992;35(5):10-1.

[15] Abhulimen TJ, Ibrahim IA, Ugwueke NT. Impact of obesity on male fertility in an Urban Nigerian town. International J Contemporary Med Res 2016;3(8):2279-82.

[16] Vanker A. Approach to the child with recurrent wheeze. Paediatric Pulmonology, Red Cross War Memorial Children's Hospital, University of Cape Town. www.scah.uct.ac.za. Accessed on 10 February 2016. 